\title{
A COMPARISON OF THREE VERSUS TWO SPUTUM SMEAR MICROSCOPY IN A GOVERNMENT MEDICAL COLLEGE, PATIALA, INDIA
}

\author{
Kishan $\mathrm{J}^{1}$, Kaur $\mathrm{P}^{2}$, Mahajan $\mathrm{A}^{3}$, Monika4 ${ }^{4}$ Navneet $\mathrm{K}^{5}$, Dulloo $\mathrm{S}^{6}$ \\ ${ }^{1}$ STDC Punjab, Government Medical College, Patiala \\ 2,3 Government Medical College, Patiala \\ ${ }^{4}$ Intermediate Reference Laboratory \\ 5,6 Interns
}

\begin{abstract}
Introduction: Under the Revised National Tuberculosis Control Programme of India, three sputum samples are examined and 2 samples positivity criteria are used for labeling the patient as sputum positive pulmonary tuberculosis. Recent studies advocate use of two samples (one spot \& one morning) for diagnosis of Tuberculosis. The objective was to compare three versus two sputum smears and to study the relevance of third sputum sample for microscopy in the current practice under Revised National Tuberculosis and Control Programme.
\end{abstract}

Methodology: A study of the laboratory register of the designated microscopic centre for the calendar year 2008 was undertaken. In all 9028 suspects were examined. An analysis of contribution of various sputum samples, S1 (first spot sample), M (early morning) \& S2 (second spot) towards diagnosis of Pulmonary Tuberculosis was undertaken.

Results: Sputum smear examination results of all the patients examined during 2008 were analyzed. Twelve hundred and eighty eight patients $(99.3 \%)$ were labeled as smear positive tuberculosis when three sputum samples positivity criteria was considered. By applying two samples and any smear positivity criteria 1296 (99.9\%) patients were labeled as sputum smear positive. Among 1296 smears, S1 was positive in $1088(83.8 \%)$ and M in $1293(99.6 \%)$ patients. Early morning sample positivity yield was found higher.

Conclusion: Considering 2 samples for examination with at least one morning specimen and one sample positivity criteria, the work load on laboratory can be reduced by $1 / 3$ rd without affecting case detection rate.

Key words: Revised National Tuberculosis Control Programme, Three sputum versus two sputum smears

\section{INTRODUCTION}

In a suspected case of pulmonary tuberculosis under the Revised National Tuberculosis Control Programme of India, 3 sputum smear examination

\footnotetext{
Correspondence:

Dr. Jai Kishan

Prof. \& Head, TB and Chest Diseases Department

Government Medical College Patiala cum

Tel: 98887744425, Fax (0175) 2220268

E mail: jaikishantb@gmail.com
}

are undertaken for diagnosing a case of pulmonary tuberculosis. However recent studies have reported that 2 sputum smear examination is enough for diagnosing pulmonary tuberculosis. ${ }^{1}$ International Standard of TB Care also advises 2 or 3 sputum smear examination for diagnosing pulmonary tuberculosis. Under the present strategy every patient has to visit the Designated Microscopy Centre for 2 days in order to get his sputum examination done. It is observed that many times some patients do not turn up for giving 
their early morning and second spot samples due to various reasons. The only sample submitted by some of these patients is found to be smear positive. This leads to increased work load for the programme staff, who have to trace these patients. So in order to see the contribution of first, second and third sputum sample for the diagnosis of pulmonary tuberculosis especially the $2^{\text {nd }}$ spot sample, a retrospective study was undertaken by the Tuberculosis and Chest Department/ Hospital Government Medical College, Patiala, India.

\section{METHODOLOGY}

Analysis of Tuberculosis laboratory register of Designated Microscopy Centre of Tuberculosis and Chest Department/Hospital Government Medical College, Patiala for calendar year 2008 was undertaken. In all 9028 suspects had undergone sputum smear examination which include those persons, who were symptomatic ( cough $>3$ weeks) and others are having cough $<3$ weeks but symptoms associated with comorbities( Diabetes Mellitus, Bronchial Asthma, Chronic Obstructive Pulmonary Disease and HIV). Result of sputum smear of first spot (S1), morning (M), and second spot (S2) smear was recorded and analyzed.

\section{RESULTS}

In 9028 patients examined, 3 sputum smears were From above table, in all 9028 positive in 1059 $(82 \%)$ patients (Table 1). 1288 (99.3\%) patients were found to be sputum smear positive when 2 sputum smear positivity was considered out of three samples. When 2 samples and 2 sputum smears positivity criteria was adopted, 1085 $(83.7 \%)$ patients were positive. Similarly, when two samples and one sputum positivity criteria was considered 1296 (99.9\%) patients were positive. Yield of early morning sample was higher than first spot specimen. If two samples and 1 smear positivity criteria is adopted instead of 3 samples and 2 positivity criteria as is being presently used, number of patients diagnosed as sputum positive will be 1296 and 1288 respectively. By applying any sample positivity criteria and ignoring the second spot sample, only 1 patient was not fulfilling the criteria of sputum positivity. While applying 2 sample criteria, out of total 1297 the morning sample was positive in 1287 (99.2\%) and negative in $1(0.07 \%)$ patients. This signifies the importance of early morning sample for the diagnosis of pulmonary tuberculosis.

By applying 3/2/1 samples and 2/1 smear positivity criteria, number of patients which could be diagnosed smear positive pulmonary TB is given in table 2. Out of 9028 suspect patients single spot sample was obtained from 1360 (15.06\%) of patients of which $63(4.6 \%)$ were found to be sputum positive (Table 1). If only one sample criteria was used then out of 9028 patients 1151 $(12.7 \%)$ patients were found to be sputum positive (Table 1 and Table 2).

\begin{tabular}{|c|c|c|c|}
\hline $\begin{array}{l}\text { No. of } \\
\text { Positive } \\
\text { Samples }\end{array}$ & $\begin{array}{l}\text { Result of various } \\
\text { sputum samples }\end{array}$ & $\begin{array}{c}\text { No. of } \\
\text { Patient } \\
\text { Positive }\end{array}$ & $\%$ \\
\hline $\begin{array}{l}\text { All } 3 \\
\text { Samples } \\
\text { positive }\end{array}$ & $\mathrm{S} 1(+), \mathrm{M}(+), \mathrm{S} 2(+)$ & 1059 & $82 \%$ \\
\hline $\begin{array}{l}\text { Any } 2 \\
\text { Samples } \\
\text { Positive }\end{array}$ & $\begin{array}{l}\mathrm{S} 1(+), \mathrm{M}(+), \mathrm{S} 2(-) \\
\mathrm{S} 1(-), \mathrm{M}(+), \mathrm{S} 2(+) \\
\mathrm{S} 1(+), \mathrm{M}(-), \mathrm{S} 2(+)\end{array}$ & $\begin{array}{c}26 \\
202 \\
1\end{array}$ & $\begin{array}{l}1.15 \% \\
15.3 \% \\
0.07 \%\end{array}$ \\
\hline $\begin{array}{l}\text { Any } 1 \\
\text { Sample } \\
\text { Positive }\end{array}$ & $\begin{array}{l}\mathrm{S} 1(+), \mathrm{M}(-), \mathrm{S} 2(-) \\
\mathrm{S} 1(-), \mathrm{M}(+), \mathrm{S} 2(-) \\
\mathrm{S} 1(-), \mathrm{M}(-), \mathrm{S} 2(+)\end{array}$ & $\begin{array}{l}2 \\
6 \\
1\end{array}$ & $\begin{array}{l}0.15 \% \\
0.23 \% \\
0.07 \%\end{array}$ \\
\hline $\begin{array}{l}\text { Only 1st } \\
\text { Spot sample } \\
\text { given in } \\
1360\end{array}$ & $\mathrm{~S} 1(+)$ & 63 & $4.6 \%$ \\
\hline $\begin{array}{l}\text { S1 }(+)=\text { Firs } \\
\text { S2 }(+)=\text { Seco } \\
\text { S1 }(-)=\text { Firs } \\
\text { S2 }(-)=\text { Seco }\end{array}$ & $\begin{array}{l}\text { spot Positive M } \\
\text { nd Spot Positive } \\
\text { t Spot Negative M } \\
\text { nd Spot Negative }\end{array}$ & & \\
\hline
\end{tabular}

Table 2. 3/2/1 sputum smears versus 2/1 Smear Positivity Criteria

\begin{tabular}{|c|c|c|}
\hline $\begin{array}{c}\text { No of } \\
\text { Sputum } \\
\text { Sample }\end{array}$ & $\begin{array}{c}\text { Positivity } \\
\text { criteria }\end{array}$ & $\begin{array}{c}\text { Patients } \\
\text { Diagnosed as } \\
\text { Sputum Positive }\end{array}$ \\
\hline 3 & 2 & $1288(99.3 \%)$ \\
\hline 2 & 2 & $1085(83.7 \%)$ \\
\hline 3 & 1 & $1297(100 \%)$ \\
\hline 2 & 1 & $1296(99.9 \%)$ \\
\hline 1 & 1 & $1151(88.7 \%)$ \\
\hline
\end{tabular}




\section{DISCUSSION}

The present study is comparable with a study by Santha et al (2000) reporting third sputum smear positivity in only $3(1.4 \%)$ out of 1715 patients. $^{3}$ A study has also reported third sputum sample positivity in only $8(<1 \%)$ out of 7927 patients and is comparable with the present study. The present study can also be compared with others who have reported third sputum sample positivity in $1(<1 \%)$ out of 2560 patients. ${ }^{4,5}$ This study is also comparable with a study by S. Rao et al, 2009 reporting third sputum smear positivity in only 12 $(2 \%)$ out of 546 patients. ${ }^{2}$ If we reduce the no. of samples from 3 to 2 , then it will reduce the work load by $1 / 3$ without much effect on case detection rate. ${ }^{1,6,7}$ If we use 1 sample and 1 positivity criteria, the number of sputum positive patients will decrease by $11.3 \%$. So it is important to take 1 spot and 1 morning sample for diagnosing the sputum positive pulmonary tuberculosis. ${ }^{2}$ However in order to have single day disposal of the patient the information, education and communication (IEC) activities under RNTCP need to be accelerated so that masses are educated enough to bring early morning sample on day 1 itself. $^{8}$ This will lead to saving for 1 day wages and cost of transport of the patient and the attendants. Thus by applying 2 samples and any one smear positivity criteria number of cases will be almost equal, but the workload will be decreased by $1 / 3^{\text {rd }}{ }^{4}$ Since early morning sample yield is higher than spot specimen, so out of two samples one should be early morning.

\section{CONCLUSIONS}

By applying 2 sputum smear criteria and 1 sputum smear positivity criteria; workload can be reduced by one third while maintaining the sensitivity of diagnosing smear positive patients. External Quality Assurance programme should be stringently applied while adopting 2 sample and 1 positivity criteria to monitor quality of sputum microscopy.

\section{ACKNOWLEGEMENTS}

Authors of this article are thankful to the staff of the designated microscopy centre TB and Chest Diseases Hospital Patiala for their cooperation in the calendar year 2008 data analysis.

\section{REFERENCES}

1. Harries AD et al. Screening tuberculosis suspects using two sputum smears. Int J Tuber Lung Dis 2000;4:36-40.

2. Rao S. Sputum smear microscopy in DOTS: Are three samples necessary? An analysis and its implications in tuberculosis control. Lung India 2009;26:3-4.

3. Santha T et al. Comparison of cough of 2 and 3 weeks to improve detection of smears -positive tuberculosis cases among out-patient in India. Int J Tuber lung Dis 2005;9:61-68.

4. Thomas A et al. Increased yield of smear positive pulmonary TB cases by screening patients with $\geq 2$ weeks cough, compared to $\geq 3$ weeks and adequacy of 2 sputum smear examination for diagnosis: Indian J Tuber 2008;55;77-83.

5. Toman K. Optimal tuberculosis case detection by direct sputum smear microscopy: How much is better. Geneva: World Health Organization; 1994.

6. Finch $D$, Beaty $C D$. Utility of a single sputum specimen in the diagnosis of tuberculosis. Chest 1997;111:1174-9.

7. Mase SR, Ramsay A, $\mathrm{Ng} \vee$ et al. Yield of serial sputum specimen examination in the diagnosis of pulmonary tuberculosis: a systematic review: Int J Tuber Ling Dis 2007;11: 485-495.

8. Van Deun A, Salim AH, Cooreman E et al. Optimal tuberculosis case detection by direct sputum smear microscopy: How much is better. Int $\mathrm{J}$ Tuber Lung Dis 2002;6:222-230. 